\title{
Organizational Context in General and Special Education: An Exploratory Investigation to Describe the Perspective of School Leaders
}

\author{
Stephanie A. Moore ${ }^{1}\left(\mathbb{D} \cdot \operatorname{Rebecca}^{\mathrm{Landa}}{ }^{2}\right.$ (D) Gazi Azad $^{3}$ (D)
}

Received: 19 April 2021 / Accepted: 14 September 2021 / Published online: 1 October 2021

(c) The Author(s) 2021

\begin{abstract}
Organizational context (e.g., climate, culture, resources) can impede or enhance implementation of evidence-based practices in general education settings or special education settings serving students with autism spectrum disorder. We examined the relations between organizational context and individual (i.e., implementation leadership, administrator- or service providerrole) or school (i.e., enrollment size, public/nonpublic school type) characteristics. Participants were administrative or service providing leaders $(n=34)$ from 11 schools in one state on the East Coast of the United States. School leaders' average ratings of the organizational context were generally more positive for special education than general education; however, greater culture stress was reported for special education. Correlation analyses indicated being an administrator and implementation leadership were positively associated with implementation climate in both education settings. Being an administrator was also positively associated with cultural effort (i.e., how hard people work towards achieving goals) in special education, but negatively associated with culture stress in general education. In special education, nonpublic schools had better climates (both learning and implementation), but more culture stress. Additionally, school enrollment size was negatively related to available resources and implementation climate in special education. Investigating the similarities and differences in organizational context across educational settings is needed in future research.
\end{abstract}

Keywords Autism spectrum disorder $\cdot$ Implementation climate $\cdot$ Inner setting $\cdot$ Organizational context

Schools are a primary service setting for youth with mental and behavioral health needs (Duong et al., 2020; Merikangas et al., 2011). The use of evidence-based practices (EBPs) is strongly recommended by professional organizations (e.g., National Association of School Psychologists, 2020) and required by federal legislation in the United States (U.S.; e.g., Every Student Succeeds Act [ESSA], 2015). However, adoption and scale-up of EBPs in U.S. schools is

Stephanie A. Moore

stephanie.moore@ucr.edu

1 School of Education, University of California Riverside, 900 University Ave, 1207 Sproul Hall, Riverside, CA 92521, USA

2 Center for Autism and Related Disorders, Kennedy Krieger Institute and Department of Psychiatry and Behavioral Sciences, Johns Hopkins School of Medicine, Baltimore, MD, USA

3 New York State Psychiatric Institute and Columbia University Medical Center, New York, NY, USA often limited (e.g., Cook et al., 2012; Ennett et al., 2003). A growing literature suggests that organizational context (i.e., climate, culture, stress, leadership, resources) impacts the quality of EBP implementation in U.S. schools (e.g., Forman $\&$ Selman, 2011). This paper is an exploratory investigation describing preliminary research on school leaders' perspectives of the organizational context for implementing EBPs in general education settings and special education settings serving students with autism spectrum disorder (ASD).

\section{General and Special Education Service Settings}

In the U.S., public education is federally mandated, and students may receive this education via two distinct, but related, systems. The general education system includes the standard curriculum and programming available to all students without modification. The special education system entitles students with identified disabilities, including ASD, to a free and 
appropriate public education that is designed to meet their individual learning needs (Individuals with Disabilities Education Act [IDEA], 2004). Once identified as eligible for special education, an Individualized Education Program (IEP) is developed that outlines the student's learning needs, sets measurable goals, and describes the special education and related services (e.g., learning accommodations, modifications to the standard curriculum, speech and language therapy, etc.) or supplementary aids the student will receive to make progress toward their identified IEP goals. Educational supports provided to students within special education must be delivered in the least restrictive environment, such that students with disabilities are educated with their peers without disabilities - in the general education environment- to the maximum extent appropriate based on their educational needs (IDEA, 2004).

Thus, students are served along a continuum of least to most restrictive educational placements. Whereas general education programming is the least restrictive option, a range of more restrictive placements are available in special education. In response to student needs, IEPs may specify placement in general education (with supplementary aids or accommodations) or a combination of instruction in a general education classroom with small-group or individual pull-out interventions in a special education classroom. More restrictive placements include tailored special education classrooms (e.g., designed for students with ASD) or nonpublic school programs (e.g., private schools approved to provide education for students with disabilities that cannot be served in public schools). Thus, for the purposes of this study, the general education setting refers to services provided as part of the standard educational curriculum. The special education setting, in contrast, refers to individualized educational services provided within the special education system (i.e., as part of an IEP), and inclusive of services provided across the placement continuum.

We focused on special education settings serving students with ASD because the prevalence rates for this diagnosis have been consistently rising, and therefore, there are increasingly more students with ASD in schools (Maenner et al., 2020; Newschaffer et al., 2005). All U.S. schools are charged with serving students with ASD using 28 evidencebased practices (ESSA, 2015; Hume et al., 2021), that are often implemented by teachers. We refer to these 28 EBPs broadly, rather than any ASD-specific intervention.

\section{Organizational Context in General and Special Education}

Unfortunately, there is limited research examining the organizational context for general versus special education settings, but this may be important for supporting tailored implementation efforts (Powell et al., 2019). Drawing from the Consolidated Framework for Implementation Research (CFIR; Damschroder et al., 2009) implementation in general and/or special education settings may be influenced by factors operating at multiple levels, including the outer setting (e.g., laws, broad policies), inner setting (e.g., school-building level leadership and climate), individual (e.g., professional role, attitudes, beliefs), intervention (e.g., compatibility with existing initiatives) and process level (e.g., planning, engaging key stakeholders, evaluating; Forman et al., 2013; Lyon \& Bruns, 2019).

The inner setting or immediate organizational context refers to constructs at the school-level that impede or enhance the quality of EBP implementation (Damschroder et al., 2009). As defined in the CFIR, some of the characteristics in the inner setting include an organization's culture, leadership, implementation climate, learning climate, and resources. In addition to examining culture (i.e., norms and values) some researchers (Fernandez et al., 2018) have also posited the importance of stress (e.g., strain, role overload) and effort (e.g., how hard people work toward achieving goals) within the organization's culture. Implementation leadership includes specific behaviors and actions taken by leaders to support EBP implementation (Aarons et al., 2014a), whereas implementation climate refers to staffs' "shared perceptions of the importance of EBP implementation" (Ehrhart et al., 2014, p. 2) and includes their perceptions of the organizational practices that support the implementation of EBPs (Lyon et al., 2018). A learning climate is one in which leaders express their own fallibility and staff feel like valuable partners when trying new methods, with sufficient time and space available for reflection (Fernandez et al., 2018). Resources include money, training, education, space, and time allocated for implementation.

Much of the research examining organizational context has been done in special education settings (Locke et al., 2019b; Suhrheinrich et al., 2020). However, there are noteworthy differences between general and special education settings, which may impact the organizational context for implementation. For example, in contrast to general education, provision of special education services follows additional regulations (i.e., IDEA, 2004), and these are related to federal and local education funding. These regulations further specify detailed procedural requirements for evaluation and intervention to which schools are held accountable. The important distinctions between general education settings and special education settings may manifest in differences in perceived stress and/or resources available for implementation. Despite these noteworthy differences, there are limited studies that compare the organizational context in general versus special education, and the factors that influence organizational context in each of these settings. 


\section{Characteristics Influencing the Organizational Context}

\section{Individual Characteristics}

In organizational theory, leaders are viewed as critical in shaping organizational contexts (Aarons et al., 2014b). School leaders are recognized as implementation drivers for general education (Eagle et al., 2015; Lyon \& Bruns, 2019; White et al., 2012) and special education (Suhrheinrich et al., 2020). We focus on the perspective of school leaders who were either working in an administrative role (e.g., principals or assistant principals) or practice role (e.g., service providers such as school psychologists or social workers). This is consistent with prior research examining dimensions of the organizational context in schools (Locke et al., 2019c; Stadnick et al., 2019), and with recognition that leadership at multiple levels can influence the organizational context for implementation (Aarons et al., 2014b). In U.S. schools, distributed leadership models using a team-based approach are common (Bush \& Glover, 2014; Locke et al., 2019c). More specifically, upper-level administrative leaders (e.g., principals, assistant principals) often approve new initiatives, establish standards, and provide accountability for implementation. However, lower-level practice leaders (e.g., school psychologist, behavior specialist, IEP case manager) are instrumental in the design of student intervention programs (e.g., by identifying EBPs to use), development of plans for EBP implementation, and support of educators (teachers, paraprofessionals) to implement EBPs (e.g., through consultation or coaching). Thus, both administrative and practice leaders are critical for implementation in schools with each having the potential to impact the organizational context for implementation (e.g., Aarons et al., 2014b).

Prior research suggests that perceptions of implementation may differ depending on the individual's role at their organization (Locke et al., 2018). For example, differences in perceptions toward EBPs and their implementation have been identified between principals and teachers (Ihmeideh \& Oliemat, 2015; Yau \& Cheng, 2014), and between principals and school psychologists (Eagle et al., 2015). Similarities and differences between administrators' and teachers' perceptions of school organizational context have also been identified (Locke et al., 2019c). It is likely that an administrator's macro view versus a practice leaders' hands-on perspective creates differences in perception of the organizational context. That is, administrators may be more likely to make strategic decisions regarding EBP implementation, whereas practice leaders often drive the effectiveness of implementation efforts (Aarons et al., 2014b).
Regardless of role, one way that school leaders may impact organizational context is through implementation leadership, which is often posited as a first step for systems change. More specifically, leadership affects implementation climate which in turn impacts individual implementers and their use of EBPs (Aarons et al., 2014b, c). In schools, Stadnick et al.'s (2019) study on EBPs for ASD showed that leadership behaviors rated by principals and school staff were linked to implementation climate. Although prior studies have examined the relation between leadership and implementation climate, they have not investigated whether leadership role has a differential impact on the organizational context of general versus special education.

\section{School Characteristics}

School characteristics may also impact organizational context for implementation. Students with ASD may attend public schools or they may be placed in nonpublic, special education schools when their high needs are unable to be addressed in public schools. It is unclear if organizational context differs in public schools verses nonpublic schools serving students with ASD. However, research in mental health services suggests that there may be differences. More specifically, organization type (i.e., private versus public sector) has been shown to impact implementation outcomes (e.g., organizational support, provider attitudes, and adoption of EBPs), such that private agencies provided greater support for EBP implementation and more positive attitudes toward adopting EBPs (Aarons et al., 2009).

School enrollment size is another characteristic that may impact organizational context. There are some studies that show a complex relation between school size and various aspects of implementation. For example, larger urban schools are likely to use school-based prevention programs more often, but less likely to have supportive principals or the capacity to organize for program implementation (Payne, 2009). In the current literature, it is unclear whether school characteristics impact the organization context differently for general versus special education settings.

\section{Current Study}

Few studies examine what characteristics influence the organizational context for implementation. Further, there is no research, to our knowledge, that depicts the organizational context for general and special education settings, nor that describes characteristics that may be related to the organizational context for EBP implementation in each of these educational settings. Thus, the purpose of this study was to examine school leaders' perspectives of the organizational context for implementation of EBPs across general 
education settings and special education settings serving students with ASD. As a preliminary exploration of school leaders' perceptions of the organizational context, we investigated the following research questions: (1) How do school leaders perceive the organizational context of general and special education settings? and (2) What individual (e.g., implementation leadership, leaders' role) and school (e.g., enrollment size, public or nonpublic school type) characteristics are associated with organizational context in general and special education settings?

\section{Methods}

\section{Participants}

Participants were 34 school leaders from 11 schools in one state on the East Coast of the U.S. We included both administrative (50\%; e.g., principal, assistant principal, director of special education) and practice leaders (50\%; e.g., school psychologist, social worker, speech/language therapist, behavior specialist, IEP manager) who can affect school change (Locke et al., 2019c). None of our participants were teachers. School teachers, although essential for effective EBP implementation, may have less agency in shaping the broader organizational context, and therefore, were not included in this exploratory investigation specifically targeting the perspective of school leaders.

Of the 34 participants, 24 worked at public schools serving both general $(n=22)$ and special $(n=24)$ education students and 10 worked at nonpublic schools serving only special education students. All participants provided responses for special education, with 22 participants also responding for general education. Table 1 summarizes participant demographic and school characteristics. Overall, most participants were female (85\%), and all identified as either White (76\%) or Black/African American (24\%). On average, participants had worked in education for approximately 15 years, with years of experience ranging from 1 to 32 years.

Schools represented were primarily public schools (73\%) with between 42 and 386 students enrolled in the Fall of 2019. Most schools were within the city's boundaries $(n=9)$ with the remaining schools being sampled from the neighboring suburban counties $(n=2)$. All public schools were operated by local school districts. The nonpublic schools $(n=3)$ examined in the present study were each part of one alternative school system, affiliated with a university, that offers educational programming and services for children with a range of disabilities (e.g., ASD, intellectual disability, emotional disability, traumatic brain injury). These schools included programs designed specifically for students with ASD. Students are referred to
Table 1 Summary of Participant Demographic and School Characteristics

\begin{tabular}{|c|c|c|}
\hline \multirow[t]{2}{*}{ Variable } & Total sample $(n=34)$ & $\begin{array}{l}\text { General } \\
\text { education only } \\
(n=22)\end{array}$ \\
\hline & $\%$ or Mean $(\mathrm{SD})$ & $\%$ or Mean $(\mathrm{SD})$ \\
\hline Female & $85 \%$ & $91 \%$ \\
\hline Age & $40(7)$ & $39(7)$ \\
\hline \multicolumn{3}{|l|}{ Racelethnicity } \\
\hline White & $77 \%$ & $64 \%$ \\
\hline Black/African American & $24 \%$ & $36 \%$ \\
\hline Asian & $0 \%$ & $0 \%$ \\
\hline Pacific Islander & $0 \%$ & $0 \%$ \\
\hline Middle Eastern & $0 \%$ & $0 \%$ \\
\hline $\begin{array}{l}\text { American Indian or Alaska } \\
\text { Native }\end{array}$ & $0 \%$ & $0 \%$ \\
\hline Hispanic/Latino & $0 \%$ & $0 \%$ \\
\hline Other & $0 \%$ & $0 \%$ \\
\hline \multicolumn{3}{|l|}{ Role } \\
\hline Administrator & $50 \%$ & $59 \%$ \\
\hline Related service provider & $50 \%$ & $41 \%$ \\
\hline Years in Education & $15(7)$ & $13(6)$ \\
\hline Fewer than 15 years & $44 \%$ & $50 \%$ \\
\hline 15 years or more & $56 \%$ & $50 \%$ \\
\hline School characteristics & $n=11$ & $n=8$ \\
\hline School size & $221(131)$ & $265(124)$ \\
\hline \multicolumn{3}{|l|}{ School type } \\
\hline Public & $73 \%$ & $100 \%$ \\
\hline Nonpublic* $^{*}$ & $27 \%$ & $0 \%$ \\
\hline
\end{tabular}

Participant demographic information is presented for the total sample of school leaders $(n=34)$, as well as for the subset of participants who responded regarding the organizational context in general education $(n=22)$

\section{$S D$ Standard Deviation}

*Nonpublic schools were private, university-affiliated schools who provided special education services to students with disabilities. Students are referred to these settings when their educational needs cannot be met in less restrictive environments; enrollment is free for students' families

attend educational programs at these nonpublic schools by the public school-based IEP teams of local school districts, whose goal is to meet students' educational needs in the least restrictive environment. Thus, students are typically referred for nonpublic school placement when their educational needs cannot be met with accommodations or modifications to the curriculum in general and/or special education settings in a local public school. Enrollment in the nonpublic schools is free to students' families (i.e., paid for by their local school district) and includes school district provided transportation from the student's home to the nonpublic school site. 


\section{Procedure}

All research procedures were approved by the Institutional Review Board (IRB) at the university and school districts. School leaders were recruited from a larger study examining implementation strategies to enhance the use of EBPs across classrooms (i.e., serving students with ASD) and home settings. All elementary schools serving students with ASD in the participating districts were eligible to be in the larger study. For the schools participating in the larger study, the senior author emailed all eligible school leaders. The senior author individually met with all school leaders who expressed interest-in eight public schools (across two districts) and three nonpublic schools (within one nonpublic school system). During the recruitment and consent visit, the senior author explained the study, answered any questions, and consented interested participants. After obtaining written informed consent, the senior author distributed the survey packets. At the public schools, one school leader did not consent to participate. Another three consented to participate but did not return their survey forms. At the nonpublic schools, all school leaders consented to participate and returned all survey forms. Surveys were collected by the study team upon completion (i.e., between 2 weeks to 2 months after distribution).

\section{Measures}

For all measures below, except for individual demographics and school characteristics, participants were asked to respond regarding implementation of EBPs for general education students as well as for special education students with ASD.

\section{Organizational Context}

Fernandez et al. (2018) developed measures to assess seven constructs of the CFIR Inner Setting domain (Damschroder et al., 2009). We focused on five of these domains: culture overall, culture stress, culture effort, learning climate, and available resources. Two domains (implementation climate (general) and leadership engagement) were not included in this research due to their redundancy with EBP implementation climate and implementation leadership measures (see additional measures descriptions below). As the original scales were developed for healthcare settings, items were modified to reflect the school context for the current study (e.g., "school" replaced "clinic") with the developer's approval. Intervention specific items on the available resources scale were worded to reflect EBPs, broadly, and to reference school specific resources (e.g., "parent" rather than "patient" awareness, "teacher" rather than "provider" buyin). Participants responded to all items using a five-point response scale $(1=$ strongly disagree, $5=$ strongly agree $)$.

Previous factor analytic research has supported the measure's factor structure, internal consistency reliability, and discriminant validity (Fernandez et al., 2018). In that work, the internal consistency reliability (i.e., inter-relatedness or shared variance among items) was assessed using Cronbach's alpha (Cronbach, 1951) and was found to be adequate ( $\alpha=0.79-0.92$; Fernandez et al., 2018). Using the same method for the present study, the internal consistency reliability of the inner setting scales ranged from $\alpha=0.51$ (available resources) to $\alpha=0.88$ (culture) for general education and $\alpha=0.74$ (culture stress) to $\alpha=0.88$ (learning climate) for special education. Mean scores were computed for each scale.

Additionally, EBP implementation climate, or the degree to which there is a supportive climate for implementation of EBPs, was measured using the Implementation Climate Scale (ICS; Ehrhart et al., 2014). Previous school-based research has supported a five-factor structure of the ICS and use of a total implementation climate score (Lyon et al., 2018). For both general and special education settings, participants responded to 15 items, using a five-point response scale $(0=$ not at all, $4=$ very great extent $)$ to indicate the degree to which they agreed with statements regarding aspects of implementation climate at their school. We measured EBP implementation climate using the ICS total score, computed by averaging responses to all items. Previous research has supported the reliability and construct validity of the ICS (Ehrhart et al., 2014). In prior school-based research, internal consistency reliability of the total EBP implementation climate score, evaluated using Cronbach's alpha (Cronbach, 1951), was adequate $(\alpha=0.93$; Lyon et al., 2018). Similarly, in this study internal consistency reliability, evaluated using Cronbach's alpha, ranged from $\alpha=0.91$ (general education) to $\alpha=0.93$ (special education).

\section{Characteristics Related to Organizational Context}

Data regarding school leaders' current role was collected via self-report using an investigator-developed demographic form, with participants' responses coded to reflect their role as practice leaders (i.e., service providers; 0) or administrative leaders (i.e., administrators; 1 ). School type as a public (0) or nonpublic (1) school was indicated using publicly available information. Student enrollment data were collected for each public school via publicly available information on the state's school report webpage (data reflect enrollment as of 8/14/2019; Maryland State Department of Education, 2020). A high-level administrator with the nonpublic school system provided student enrollment 
information to the study team (data reflect enrollment as of 10/1/2019).

Implementation leadership, or the degree to which school leadership is supportive of implementation of EBPs, was assessed using the Implementation Leadership Scale (ILS; Aarons et al., 2014a). Participating school leaders responded to 12 -items using a five-point response scale $(0=$ not at all, $4=$ very great extent ) to indicate the degree to which they engage in various leadership behaviors. Previous research has supported a four-factor structure of the ILS and a higherorder implementation leadership factor (Aarons et al., 2014a; Lyon et al., 2018). Mean scores for overall implementation leadership for general education and special education were used. Consistent with previous research, internal consistency reliability, evaluated using Cronbach's alpha (Cronbach, 1951), for overall implementation leadership was adequate for both education settings in this study ( $\alpha=0.93-0.94$; Aarons et al., 2014a; Lyon et al., 2018).

\section{Data Analysis}

Given the small sample size and preliminary nature of this exploratory investigation, descriptive analyses were used to provide information about school leaders' perceptions of the organizational context for implementation of EBPs in general education settings and special education settings serving students with ASD. Descriptive studies are a critical part of the scientific process, particularly for newer research areas such as the topic of this research (Loeb et al., 2017). Common techniques used for descriptive analyses include measures of central tendency and variation (i.e., means and standard deviations) and correlations (Loeb et al., 2017). Thus, to investigate our research questions, we first describe school leaders' perceptions of the organizational context in each setting via their average (i.e., mean) ratings on organizational context measures. Then, we use point biserial (for relations between dichotomous and continuous variables) and Pearson (for relations between continuous variables) correlations to describe the association between individual (i.e., implementation leadership and participants role as an administrative or practice leader; Locke et al., 2019c; Lyon et al., 2018; Williams et al., 2020) and school (i.e., student enrollment size and public or nonpublic school type; Aarons et al., 2009; Payne, 2009) characteristics and their association with the organizational context domains in general and special education settings. Leaders in nonpublic schools did not report on implementation in general education settings; thus, the relation between school type and organizational context was only described for special education.

A power analysis was performed to determine the sample size required to detect significant relations using correlations (Cohen et al., 1988; Faul et al., 2009). Only two prior studies, to our knowledge, have explored the relations between variables of interest in the current research; each of these prior studies examined the relation between implementation leadership and implementation climate in education settings. Locke et al., (2019b) reported a significant correlation of 0.77 between implementation leadership and EBP implementation climate for special education and Lyon et al. (2018) found a correlation of 0.85 among factor scores for the ICS and the ILS for education settings, broadly. Based on the two-tailed exact test for bivariate correlations and using G*Power 3.1 (Faul et al., 2009), a sample size of 10 was required to achieve $80 \%$ power to detect significant effects of the same magnitude identified in the Locke et al. (2019b) study (i.e., $r=0.77$; statistical significance threshold set at $p=0.05$ ). Thus, our study was adequately powered to identify effects of similar magnitude.

Due to the preliminary and descriptive nature of these analyses, the associations between variables were first evaluated using the standard $p$-value of 0.05 to determine statistical significance. The strength of observed relations, also referred to as their effect size, was further interpreted (Sun et al., 2010). Prior researchers have recommended that effect sizes be interpreted within the context of similar research (e.g., Cohen, 1988; Hill et al., 2008); however, limited research has investigated the organizational context in educational settings. Thus, we interpreted the strength of the observed associations within the context of the broader psychological and educational research. Across studies, a "medium" strength effect (i.e., between the $25^{\text {th }}$ and $75^{\text {th }}$ percentiles of all effects reviewed) can be considered to fall between $|r|=0.09$ and 0.26 (Bosco et al., 2015) or $|r|=0.15$ to 0.35 (Hemphill, 2003). Values above this range are large compared to what has been observed in the broader literature whereas values below this range are smaller in comparison.

Despite the nested nature of the data (i.e., leaders within schools), this study was not well-suited for multilevel analyses, which would account for potential variability between schools, due to our limited sample size and the small size of school clusters (i.e., two schools had only one school leader participate; average participants per school was 3 , range 1 to 5). These features challenged variance estimation at the school level and limited our ability to compute intra-class correlation coefficients (ICCs) the correlation among leaders' ratings within the same school-for several organizational context variables. ICCs that were able to be computed provided mixed evidence of meaningful variability in organizational context ratings across schools (range 0.04 to 0.32 ; all $p>0.05$ ). See Supplementary Table 1 for descriptive statistics for study variables disaggregated by school number. Instead, we evaluated the robustness of the results obtained from correlation analyses to potential variation between schools via sensitivity analyses that accounted for the effect of school. That is, when examining the association between variables 
at the individual level (i.e., individual characteristics and school leader rated organizational context variables) we computed additional correlation coefficients using groupmean centered data (i.e., subtracted the respective school means from each individual value) for the variables of interest to see if observed relations held after controlling for school effects (Meinck \& Rodriguez, 2013). Variation in observed associations is described below.

\section{Results}

\section{Organizational Context in General and Special Education}

School leaders' average ratings for each organizational context domain are presented in Table 2. For both general and special education, the range of mean scores reflected response options of "neutral" (3) to "agree" (4) for inner setting domains and "moderate" (2) to "a great extent" (3) for EBP implementation climate. In both settings, leaders' ratings of the inner setting were highest (i.e., more positive) for the domains of culture effort and learning climate, and lowest for available resources and culture stress. Across most domains, school leaders' perceptions of the organizational context were more positive for special education than for general education, with the largest mean differences observed for the available resources and EBP implementation climate domains. Exceptions included greater reported culture stress in special education and similar ratings for the inner setting domains of culture and culture effort.

Table 2 Descriptive statistics for organizational context in general and special education settings

\begin{tabular}{llllll}
\hline & \multicolumn{2}{l}{$\begin{array}{l}\text { General educa- } \\
\text { tion }\end{array}$} & & \multicolumn{2}{l}{$\begin{array}{l}\text { Special educa- } \\
\text { tion }\end{array}$} \\
\cline { 2 - 2 } Scale & Mean & SD & & Mean & SD \\
\hline Inner setting & $n=22$ & & & $n=34$ & \\
Culture & 3.7 & 0.6 & & 3.8 & 0.5 \\
Culture stress & 3.3 & 0.7 & 3.5 & 0.8 \\
Culture effort & 4.0 & 0.6 & & 4.0 & 0.7 \\
Learning climate & 3.9 & 0.7 & & 4.0 & 0.7 \\
Available resources & 3.3 & 0.6 & & 3.5 & 0.7 \\
EBP implementation climate & 2.6 & 0.8 & 2.8 & 0.7 \\
\hline
\end{tabular}

Response options for Implementation Climate items were $0=n o t$ at all to 4=very great extent and for Inner Setting items were $1=$ strongly disagree, $5=$ strongly agree

$S D$ Standard Deviation, EBP Evidence-Based Practice

\section{Relation Between Individual and School Characteristics and Organizational Context}

We examined correlations between individual and school characteristics with organizational context domains (see Table 3; Supplementary Table 2 presents these results with shading to represent the magnitude of the association between the two target variables). Supplementary Table 3 presents correlation coefficients for individual characteristics and organizational context variables after accounting for school effects. We focus our description below on those associations that were statistically significant at $p<0.05$.

Considering individual characteristics, school leader's role $(r=0.63)$ and implementation leadership $(r=0.59)$ were each positively correlated with EBP implementation climate in general education. In contrast, school leader's role was negatively associated with culture stress $(r=-0.51)$ in general education. The size of these associations is large in comparison to what has been observed in the broader psychological and educational research literature (Bosco et al., 2015; Hemphill, 2003). There was a tendency for administrative leaders to report higher EBP implementation climate, as well as less culture stress in general education settings, as compared to practice leaders. School leaders who reported greater implementation leadership also tended to report a more positive EBP implementation climate in general education. These associations were robust in magnitude (i.e., similar strength) and direction when accounting for school effects via group-mean centering (see Supplementary Table 3).

For special education settings, school leader's role was similarly positively correlated with EBP implementation climate $(r=0.56)$; the size of this association was large and was robust to sensitivity analyses. Associations between school leader's role, culture, and culture effort varied when accounting for school effects. More specifically, leader's role and culture were not significantly related, but school leader's role was positively correlated with culture effort $(r=0.43$; see Supplementary Table 3 ). When variability between schools was accounted for, there was a tendency for administrative leaders, compared to practice leaders, to report more culture effort in special education. The size of this relation was large. Finally, implementation leadership was positively correlated with EBP implementation climate $(r=0.64)$, such that leaders' reporting greater leadership tended to also report a more positive implementation climate. This effect was also large in magnitude and was robust to school effects.

No significant relations were observed between the inner setting domains or EBP implementation climate in general education and school size. For special education, student enrollment size was negatively correlated with available resources $(r=-0.49)$ and EBP implementation climate $(r=-0.37)$. The size of these associations was large. School 
Table 3 Bivariate correlations for organizational context, individual characteristics, and school characteristics in general and special education settings

\begin{tabular}{|c|c|c|c|c|c|c|c|c|c|c|}
\hline & 1 & 2 & 3 & 4 & 5 & 6 & 7 & 8 & 9 & 10 \\
\hline 1. School type $(1=$ nonpublic $)$ & - & - & - & - & - & - & - & - & - & - \\
\hline 2. Student enrollment size & $-.56^{*}$ & - & -.01 & .24 & .22 & .19 & .15 & -.25 & .05 & -.03 \\
\hline 3. Leader role $(1=$ administrator $)$ & .26 & -.01 & - & $.51 *$ & $.63^{*}$ & .33 & $-.51 *$ & .23 & .42 & .38 \\
\hline 4. Implementation leadership & $.44^{*}$ & -.22 & .29 & - & $.59^{*}$ & .07 & -.22 & .05 & .38 & -.08 \\
\hline 5. EBP implementation climate & $.43^{*}$ & $-.37 *$ & $.56^{*}$ & $.64 *$ & - & $.69 *$ & $-.43 *$ & $.57 *$ & $.80 *$ & .31 \\
\hline 6. IS: culture & .29 & -.16 & $.36^{*}$ & .09 & $.67 *$ & - & -.34 & $.64 *$ & $.64 *$ & $.55^{*}$ \\
\hline 7. IS: culture stress & $.36^{*}$ & .00 & -.22 & .00 & -.08 & -.09 & - & -.13 & -.22 & -.33 \\
\hline 8. IS: culture effort & .01 & -.20 & .29 & .00 & $.59 *$ & $.50 *$ & -.18 & - & $.59 *$ & .34 \\
\hline 9. IS: learning climate & $.52 *$ & -.33 & .29 & .27 & $.66^{*}$ & $.69 *$ & .04 & $.41 *$ & - & .40 \\
\hline 10. IS: available resources & .31 & $-.49 *$ & .33 & .25 & $.65^{*}$ & $.52 *$ & -.18 & $.43^{*}$ & $.58^{*}$ & - \\
\hline
\end{tabular}

EBP Evidence-Based Practice, IS Inner Setting

Correlations for variables in special education settings are below the diagonal and correlations for variables in general education settings are above the diagonal

*Correlation is significant at the $p<.05$ level

type as either public or nonpublic was positively correlated with the inner setting domains of culture stress $(r=0.36)$ and learning climate $(r=0.52)$, and with EBP implementation climate $(r=0.43)$ in special education settings. There was a tendency for leaders at nonpublic schools to provide more positive ratings of these organizational context domains. The size of these associations was also large.

\section{Discussion}

Organizational context is important for high-quality EBP implementation, and the subsequent effectiveness of schoolbased intervention programs (Kratz et al., 2019; Locke et al., 2019c). We examined school leaders' perceptions of the organizational context in general education settings and special education settings for students with ASD. Specifically, we first described the organizational context (i.e., inner setting domains and EBP implementation climate) for general and special education from the perspective of school leaders, including administrative leaders (principals, assistant principals) and practice leaders (school psychologists, social workers, school counselors, etc.). We then described the relations between individual leader characteristics, specifically their role at the school and self-reported leadership, and school characteristics, such as student enrollment size and public/nonpublic school type, with organizational context domains. Although preliminary and descriptive, this study extends previous research, most often conducted in special education settings, and supports further investigation of the organizational context in both general and special education settings. Our main observations are highlighted below, including discussion of their implications for future school-based implementation research and practice.

\section{School Leaders' Perceptions of the Organizational Context in General and Special Education}

School leaders described a similar pattern of strengths and weaknesses for general and special education across the inner setting and EBP implementation climate domains. Overall, school leaders had the most positive perceptions of the inner setting domains of culture effort (i.e., "how hard people in their organizations work toward achieving goals") and learning climate (i.e., climate in which leaders express fallibility/need for assistance and team members feel valued, safe, and able to reflect; Fernandez et al., 2018, p. 4). Their perceptions were lowest for the inner setting domain of culture stress (i.e., perceived strain, stress, and role overload) and available resources (i.e., amount of resources dedicated for implementation and ongoing operations, including budget/financial resources, training, staff, equipment/materials, buy-in, awareness/need; Fernandez et al., 2018). Our finding for available resources is consistent with previous literature showing that school staff reported limited support in terms of tangible materials for EBP use (Locke et al., 2019c). On average, school leaders also reported that the general and/or special education settings in their schools were characterized by a moderately to greatly supportive climate for EBP implementation.

School leaders' average ratings of the organizational context for special education were often more positive (in terms of culture effort, learning climate, available resources, and EBP implementation climate), than their ratings for general education, with the greatest differences observed for 
available resources and EBP implementation climate. This suggests that school leaders perceive there to be more available resources and better implementation climate in special education service settings. Yet, on average, more culture stress was also reported in special education settings. Although large urban schools often report limited resources, our results indicate that having resources available, and a positive climate for implementation, may not be sufficient to reduce stress in special education settings. This is consistent with a large body of research that has documented high levels of educator (i.e., teacher) stress in special education settings (e.g., Brunsting et al., 2014). It is possible that the increased emphasis on EBPs and complexity of intervention design, implementation, and evaluation in special education, especially for ASD, contributes to more stress in this setting.

\section{Individual, School Characteristics and Organizational Context}

Several noteworthy relations were identified between individual and school characteristics with organizational context domains. First, implementation leadership was positively related to EBP implementation climate in both general and special education settings. Specifically, greater implementation leadership was associated with a more positive EBP implementation climate. This is consistent with organizational theory and the accumulating evidence that leadership is a critical factor for implementation climate (e.g., Aarons et al., 2014c; Stadnick et al., 2019). A positive implementation climate is important because it impacts the use of EBPs by individuals working in that organization (Lyon et al., 2018; Williams et al., 2020). Implementation leadership and EBP implementation climate have been described as "proximal" to implementer behavior and pertinent for EBP implementation (Locke et al., 2019c; Lyon et al., 2018). Although the strength of the relations we observed were somewhat smaller ( $r=0.59$ and 0.64 for general and special education, respectively) than what has been found in prior research in special education (e.g., $r=0.77$; Locke et al., 2019b), this study contributes to the literature because it suggests that implementation leadership is important in promoting a positive implementation climate across education settings.

However, implementation leadership was not significantly associated with other aspects of the organizational context in each educational setting, including culture, culture stress, learning climate, and available resources. Although we observed implementation leadership behavior to be related to implementation climate, it seems that these leadership behaviors may be less important in contributing to the other domains of a school's organizational context. Although constructs such as culture, stress, and learning climate (subconstruct of general implementation climate) are important for understanding organizational functioning, these aspects of the organizational context are relatively more distally related to EBP implementation outcomes. In contrast, EBP implementation climate and implementation leadership have been shown to be more directly related to EBP implementation outcomes (Ehrhart et al., 2014; Lyon et al., 2018; Williams et al., 2020). It is possible that other facets of school leadership that were not examined in the present study (e.g., transformational leadership; Atasoy, 2020; Leithwood \& Jantzi, 2005), rather than strategic leadership behaviors specific to EBP implementation, are important in shaping these broader aspects (i.e., culture, culture stress, learning climate, and available resources) of a school's organizational context. Alternatively, it may be that strategic leadership behaviors effect these molar constructs through mediating variables (e.g., years of experience).

Second, school leader's role was related to their perception of several organizational context domains. For example, administrative leaders, tended to hold more positive perceptions of the EBP implementation climate in both general and special education settings than did practice leaders. Additionally, administrative leaders tended to report less culture stress in general education and, after accounting for variability across schools, more culture effort (i.e., how hard people in their organizations work toward achieving goals) in special education. These results are congruent with previous research in school and clinic settings indicating that school stakeholders' perceptions of implementation may differ depending on their role (e.g., Eagle et al., 2015; Laschober \& Eby, 2013). In the literature, practice leaders are reported to provide more content expertise, including data-based decision-making, curricular and instructional methodology, evidence-based intervention, and systematic problem-solving procedures (i.e., competency drivers). In contrast, administrative leaders serve as organizational drivers by fostering environments that support effective and sustainable implementation practices (Eagle et al., 2015). Given that administrative leaders are not directly involved in service delivery, they may hold more positive perceptions of the implementation climate than service providers who are more involved in EBP implementation (e.g., through training or coaching teachers). Further, it may be that administrators' direct involvement in establishing the standards and accountability indicators for EBP implementation contributes to their more positive perceptions of implementation climate in both education settings (Locke et al., 2019b).

Finally, school structural characteristics of student enrollment size and public or nonpublic school type were related to selected organizational context domains in special education settings only. More specifically, larger enrollment size was associated with less positive ratings of the implementation climate. Additionally, larger student enrollment size was associated with fewer available resources in special education. It is not surprising that stakeholders in larger schools 
rated fewer resources (e.g., budgetary/financial, training, personnel, equipment/materials, buy-in, awareness/need) to be available for special education service provision, especially given the context in which the current study was conducted. A majority of the schools included in our sample are in a large urban school district in a densely populated metropolitan city serving low-income communities. Prior research has found that special education teachers in a large urban school district perceived there to be fewer resources (e.g., training, professional development, curriculum), particularly of appropriate quality and relevance, to support service provision in special education compared to general education (Cavendish et al., 2020).

Additionally, compared to leaders working in special education in public schools, leaders working in nonpublic schools tended to report a more positive learning climate and EBP implementation climate. With regard to learning climate, it is possible that in nonpublic settings where all staff are charged with keeping abreast of EBPs for ASD, school leaders feel more comfortable expressing their fallibility or need for assistance, and in turn, their team members feel more valued, safe, and able to reflect. It is important to note that in our study, enrollment size was also correlated with school type in special education. Therefore, these preliminary findings suggest a complex relation between enrollment size, school type, resources, and implementation climate.

We also found that school leaders working in nonpublic settings reported more culture stress. These results are somewhat supported by prior research in mental health services, which found that support for implementation was greater in private agencies than in public agencies (Aarons et al., 2009). In the present study, we worked with a universityaffiliated, nonpublic school system serving students with ASD whose educational needs were unable to be met in less restrictive settings. In such settings, there is great investment in the implementation of EBPs (Pas et al., 2016), and this may create stress for school leaders. In nonpublic settings, school leaders may feel increased pressure to ensure that teachers are implementing EBPs for their high needs student population and satisfy the demands of parents. Additional research is needed to replicate and further investigate the observed relations in this study, including potential mechanisms for the associations between these organizational context domains and school characteristics.

\section{Limitations, Future Directions, and Implications}

Results are interpreted with important limitations in mind. Given the limited research in this area, this study is a first attempt to describe the organizational context in general and special education settings from the perspective of school leaders, which is a particularly difficult sample to engage in research. We acknowledge that the small sample size may have limited our ability to detect small- or medium-sized effects. Although our study had adequate power to detect statistically significant relations that were similar in magnitude to prior research that investigated the relation between implementation leadership and implementation climate (i.e., Locke et al., 2019b; Lyon et al., 2018), a sample size of 61 or larger would have been needed to achieve $80 \%$ power to detect effects identified to be of "medium" strength in the broader psychological and educational literature (i.e., $r \leq 0.35$; e.g., Bosco et al., 2015; Hemphill, 2003). Thus, it is unclear whether the non-significant relations we observed accurately indicate no relation between variables, or if null findings were a result of limitations in power to detect significant small effects. Despite our sample size limitation, our study signals potentially meaningful relations between individual and school characteristics with organizational context domains that warrant further research.

We were also unable to perform multilevel analyses due to our small sample size and the size of school clusters. However, sensitivity analyses accounting for school-level variance indicated the majority of our results to be robust. Nevertheless, it is imperative that the results of this preliminary, descriptive study be replicated and extended in larger samples.

Future research with more robust samples of school leaders is needed to further understand relations between individual and school characteristics with organizational context domains across educational settings, including driving mechanisms of these effects, as well as how organizational context domains interact and influence school-based implementation by teachers. For example, additional research is needed to parse out the effects of school type with organizational context in each education setting. Whereas the public schools included in our sample were representative of both general and special education settings, nonpublic schools only reflected special education settings. Future research should investigate possible interactions between school type, educational setting, individual and school characteristics and their impacts on the organizational context. It will also be critical for future research to include comprehensive comparison groups, such as examining the organizational context for services provided to students in general education who are receiving special education supports versus students in general education not receiving special education supports. It is equally important to examine the range of restrictive educational settings possible for students with ASD, beyond the university-affiliated nonpublic setting that was examined in the present study. Therefore, there are limitations to the generalizability of our results given the characteristics of our sample and setting. However, the diversity in school leaders' roles and school type in this sample, reflect the "real world" of schools, where conducting highly controlled and "neat" implementation studies are challenging. Thus, whereas this 
study's results provide initial information about the organizational context for EBP implementation across educational settings, future research and replication of these findings with additional samples are needed.

Research that qualitatively explores school leaders' perceptions of the organizational context in education settings is important in further illustrating the observations made in this study. Moreover, assessing the relation between school leaders' perceptions of the organizational context and their implementation practices and/or implementation outcomes is another necessary direction for future research. It will be important to also examine education providers', such as general and special education teachers', perspectives of the organizational context in general and special education, including potential discrepancies in the perceptions of the organizational context across stakeholder groups. Finally, the inner setting measures used in this research were not designed for educational settings. These measurement limitations may have contributed to the low internal consistency observed for the available resources domain in general education.

Despite these limitations, the results of our preliminary research have important implications for school-based implementation research and practice. Our results signal potential areas of similarity and difference in the organizational context domains of general and special education settings in U.S. schools. More research is needed to understand the mechanisms by which organizational context may influence educators' EBP use. For example, it will be important to examine whether implementation climate mediates the relation between implementation leadership and educators' use of EBPs (Locke et al., 2019b; Williams et al., 2020). Given the interacting nature of implementation determinants at multiple levels (Damschroder et al., 2009), future research should include both individual and organizational factors when examining EBP use (Locke et al., 2019b), and examine these for both general education settings and special education settings. Further, although school structural characteristics, such as school size and type, were related to dimensions of the organizational context, future research should also consider examining how more malleable school characteristics (e.g., team infrastructure and stability, centralization of decision-making) may impact the organizational context of general and special education and ultimately, educators' use of EBPs in each setting (Damschroder et al., 2009; Locke et al., 2019a).

Our results signal that the organizational context in which EBPs are implemented for general and special education settings (serving students with ASD) in the U.S. may vary. In special education, the relatively stronger EBP implementation climate was tempered by somewhat greater experiences of culture stress. Thus, school stakeholders may need to provide additional supports to manage the relatively greater degree of culture stress present in special education. For example, prior to introducing new EBPs or in efforts to scale-up existing EBPs, leaders can work to reduce staff experiences of stress, frustration, and heavy workload that negatively impacts their effectiveness through coordinated initiatives targeting staff wellness, reviewing existing initiatives to ensure alignment with the school's current goals and needs, and trimming redundant, overly burdensome, or ineffective initiatives (e.g., Cook et al., 2019).

Similarly, our preliminary results indicate that individual characteristics, including school leaders' role and leadership, may be influential for developing a positive EBP implementation climate to support EBP use in special education. Given the consistent relation between school leaders' implementation leadership with implementation climate, our findings further support the importance of organization-level support that can enhance coordinated leadership among school-based leadership teams (Aarons et al., 2015). Differences in perceptions of the organizational context based on school leaders' role also highlight the importance of coordinated, team-based approaches in promoting the effective implementation of EBPs (Locke et al., 2019b). Additionally, school leaders' role and structural school characteristics (i.e., school type and student enrollment size) may be pertinent in understanding a school's culture, specifically in special education settings. It is imperative for school leaders to understand their school's organizational context in order to take a tailored approach to supporting EBP implementation, and ultimately to enhance outcomes for students.

Supplementary Information The online version contains supplementary material available at https://doi.org/10.1007/s43477-021-00023-2.

Acknowledgements The authors would like to thank staff from Maryland schools who participated in this study. This study was supported in part by a Faculty-Community Award from the Urban Health Institute at Johns Hopkins University (74210; PI: Azad). Preparation of this article was supported in part by grants from the National Institute of Mental Health (T32MH109436; SM; PI: Barry; 7K23MH119331-02; GA; PI: Azad).

\section{Declarations}

Conflict of interest The authors declare that they have no conflict of interest.

Open Access This article is licensed under a Creative Commons Attribution 4.0 International License, which permits use, sharing, adaptation, distribution and reproduction in any medium or format, as long as you give appropriate credit to the original author(s) and the source, provide a link to the Creative Commons licence, and indicate if changes were made. The images or other third party material in this article are included in the article's Creative Commons licence, unless indicated otherwise in a credit line to the material. If material is not included in the article's Creative Commons licence and your intended use is not permitted by statutory regulation or exceeds the permitted use, you will 
need to obtain permission directly from the copyright holder. To view a copy of this licence, visit http://creativecommons.org/licenses/by/4.0/.

\section{References}

Aarons, G. A., Ehrhart, M. G., \& Farahnak, L. R. (2014a). The Implementation Leadership Scale (ILS): Development of a brief measure of unit level implementation leadership. Implementation Science, 9, 45. https://doi.org/10.1186/1748-5908-9-45

Aarons, G. A., Ehrhart, M. G., Farahnak, L. R., \& Hulburt, M. S. (2015). Leadership and organizational change for implementation (LOCI): A randomized mixed method pilot study of a leadership and organizational development intervention for evidence-based practice implementation. Implementation Science, 10, 11. https:// doi.org/10.1186/s13012-014-0192-y

Aarons, G. A., Ehrhart, M. G., Farahnak, L. R., \& Sklar, M. (2014b). Aligning leadership across systems and organizations to develop a strategic climate for evidence-based practice implementation. Annual Review of Public Health, 35, 255-275. https://doi.org/10. 1146/annurev-publhealth-032013-182447

Aarons, G. A., Ehrhart, M. G., Farahnak, L. R., \& Sklar, M. (2014c). The role of leadership in creating a strategic climate for evidencebased practice implementation and sustainment in systems and organizations. Frontiers in Public Health Services and Systems Research. https://doi.org/10.13023/FPHSSR.0304.03.

Aarons, G. A., Sommerfeld, D. H., \& Walrath-Greene, C. M. (2009). Evidence-based practice implementation: The impact of public versus private sector organization type on organizational support, provider attitudes, and adoption of evidence-based practice. Implementation Science, 4, 83. https://doi.org/10.1186/ 1748-5908-4-83

Atasoy, R. (2020). The relationship between school principals' leadership styles, school culture, and organizational change. International Journal of Progressive Education, 16(5), 257-274. https:// doi.org/10.29329/ijpe.2020.277.16.

Bosco, F. A., Aguinis, H., Singh, K., Field, J. G., \& Pierce, C. A. (2015). Correlational effect size benchmarks. Journal of Applied Psychology, 100(2), 431-449. https://doi.org/10.1037/a0038047

Brunsting, N. C., Sreckovic, M. A., \& Lane, K. L. (2014). Special education teacher burnout: A synthesis of research from 1979 to 2013. Education and Treatment of Children, 37(4), 681-711. https://doi.org/10.1353/etc.2014.0032

Bush, T., \& Glover, D. (2014). School leadership models: What do we know? School Leadership \& Management, 35(5), 553-571. https://doi.org/10.1080/13632434.2014.928680

Cavendish, W., Morris, C. T., Chapman, L. A., Ocasio-Stoutenburg, L., \& Kibler, K. (2020). Teacher perceptions of implementation practices to support secondary students in special education. Preventing School Failure: Alternative Education for Children and Youth, 64(1), 19-27. https://doi.org/10.1080/1045988X.2019.1628000

Cohen, J. (1988). Statistical power analysis for the behavioral sciences. Routledge.

Cook, C. R., Lyon, A. R., Locke, J., Waltz, T., \& Powell, B. J. (2019). Adapting a compilation of implementation strategies to advance school-based implementation research and practice. Prevention Science, 20, 914-935. https://doi.org/10.1007/ s11121-019-01017-1

Cook, B. G., Smith, G. J., \& Tankersley, M. (2012). Evidence-based practices in education. In K. R. Harris, S. Graham, T. Urdan, C. B. McCormick, G. M. Sinatra, \& J. Sweller (Eds.), APA handbooks in psychology®. APA educational psychology handbook, Vol. 1. Theories, constructs, and critical issues (p. 495-527). American Psychological Association. https://doi.org/10.1037/13273-01
Cronbach, L. (1951). Coefficient alpha and the internal structure of tests. Psychometrika, 16, 297-334. https://doi.org/10.1007/BF023 10555

Damschroder, L. J., Aron, D. C., Keith, R. E., Kirsh, S. R., Alexander, J. A., \& Lowery, J. C. (2009). Fostering implementation of health services research findings into practice: A consolidated framework for advancing implementation science. Implementation Science, 4, 50. https://doi.org/10.1186/1748-5908-4-50

Duong, M. T., Bruns, E. J., Lee, K., Cox, S., Coifman, J., Mayworm, A., \& Lyon, A. R. (2020). Rates of mental health service utilization by children and adolescents in schools and other common service settings: A systematic review and meta-analysis. Administration and Policy in Mental Health and Health Services Research. https://doi.org/10.1007/s10488-020-01080-9

Eagle, J. W., Dowd-Eagle, S. E., Snyder, A., \& Holtzman, E. G. (2015). Implementing a multi-tiered system of support (MTSS): Collaboration between school psychologists and administrators to promote systems-level change. Journal of Educational and Psychological Consultation, 25(2-3), 160-177. https://doi.org/ 10.1080/10474412.2014.929960

Ehrhart, M. G., Aarons, G. A., \& Farahnak, L. R. (2014). Assessing the organizational context for EBP implementation: The development and validity testing of the Implementation Climate Scale (ICS). Implementation Science, 9, 157. https://doi.org/10. 1186/s13012-014-0157-1

Ennett, S. T., Ringwalt, C. L., Thorne, J., Rohrbach, L. A., Vincus, A., Simons-Rudolph, A., \& Jones, S. (2003). A comparison of current practice in school-based substance use prevention programs with meta-analysis findings. Prevention Science, 4, 1-14.

Every Student Succeeds Act, 20 U.S.C. $\S \S 6301$ et seq. (2015).

Faul, F., Erdfelder, E., Buchner, A., \& Lang, A.-G. (2009). Statistical power analyses using $\mathrm{G}^{*}$ Power 3.1: Tests for correlation and regression analyses. Behavior Research Methods, 41, 11491160. https://doi.org/10.3758/BRM.41.4.1149

Fernandez, M. E., Walker, T. J., Weiner, B. J., Calo, W. A., Liang, S., Risendal, B., Friedman, D. B., Tu, S. P., Williams, R. S., Jacobs, S., Herrmann, A. K., \& Kegler, M. C. (2018). Developing measures to assess constructs from the Inner Setting domain of the Consolidated Framework for Implementation Research. Implementation Science, 13, 52. https://doi.org/10. 1186/s13012-018-0736-7

Forman, S. G., Shapiro, E. S., Codding, R. S., Gonzales, J. E., Reddy, L. A., Rosenfield, S. A., Sanetti, L. M. H., \& Stoiber, K. C. (2013). Implementation science and school psychology. School Psychology Quarterly, 28(2), 77-100. https://doi.org/10.1037/ spq0000019

Forman, S. G., \& Selman, J. S. (2011). Systems-based service delivery in school psychology. In M. A. Bray \& T. J. Kehle (Eds.), Oxford handbook of school psychology (pp. 628-646). Oxford University Press.

Hemphill, J. F. (2003). Interpreting the magnitudes of correlation coefficients. American Psychologist, 58(1), 78-79. https://doi.org/10. 1037/0003-066X.58.1.78

Hill, C. J., Bloom, H. S., Black, A. R., \& Lipsey, M. W. (2008). Empirical benchmarks for interpreting effect sizes in research. Child Development Perspectives, 2(3), 172-177. https://doi.org/10. $1111 / \mathrm{j} .1750-8606.2008 .00061 . \mathrm{x}$

Hume, K., Steinbrenner, J. R., Odom, S. L., Morin, K. L., Nowell, S. W., Tomaszweski, B., Szendrey, S., McIntyre, N. S., YücesoyÖzkan, S., \& Savage, M. N. (2021). Evidence-based practices for children, youth, and young adults with Autism: Third generation review. Journal of Autism and Developmental Disorders. https:// doi.org/10.1007/s10803-020-04844-2

Ihmeideh, F., \& Oliemat, E. (2015). The effectiveness of family involvement in early childhood programmes: Perceptions of kindergarten principals and teachers. Early Child Development and 
Care, 185(2), 181-197. https://doi.org/10.1080/03004430.2014. 915817

Individuals With Disabilities Education Act, 20 U.S.C. § 1400 (2004). Kratz, H. E., Stahmer, A., Xie, M., Marcus, S. C., Pellecchia, M., Locke, J., Beidas, R., \& Mandell, D. S. (2019). The effect of implementation climate on program fidelity and student outcomes in autism support classrooms. Journal of Consulting and Clinical Psychology, 87(3), 270-281. https://doi.org/10.1037/ccp0000368

Laschober, T. C., \& Eby, L. T. (2013). Counselor and clinical supervisor perceptions of OASAS tobacco-free regulation implementation extensiveness, perceived accountability, and use of resources. Journal of Psychoactive Drugs, 45(5), 416-424. https://doi.org/ $10.1080 / 02791072.2013 .845329$

Leithwood, K., \& Jantzi, D. (2005). A review of transformational school leadership research: 1996-2005. Leadership and Policy in Schools, 4, 177-199. https://doi.org/10.1080/15700760500244769

Locke, J., Kang-Yi, C., Frederick, L., \& Mandell, D. S. (2019a). Individual and organizational characteristics predicting intervention use for children with autism in schools. Autism. https://doi.org/10. $1177 / 1362361319895923$

Locke, J., Lawson, G. M., Beidas, R. S., Aarons, G. A., Xie, M., Lyon, A. R., Stahmer, A., Seidman, M., Frederick, L., Oh, C., Spaulding, C., Dorsey, S., \& Mandell, D. S. (2019b). Individual and organizational factors that affect implementation of evidence-based practices for children with autism in public schools: A cross-sectional observational study. Implementation Science, 14(1), 29. https:// doi.org/10.1186/s13012-019-0877-3

Locke, J., Lee, K., Cook, C. R., Frederick, L., Vázquez-Colón, C., Ehrhart, M. G., Aarons, G. A., Davis, C., \& Lyon, A. R. (2019c). Understanding the organizational implementation context of schools: A qualitative study of school district administrators, principals, and teachers. School Mental Health, 11, 379-399. https:// doi.org/10.1007/s12310-018-9292-1

Locke, J., Violante, S., Pullman, M. D., Kerna, S. E. U., Jungbluth, N., \& Dorsey, S. (2018). Agreement and discrepancy between supervisor and clinical alliance: Associations with clincians' perceptions of psychological climate and emotional exhaustion. Administration and Policy in Mental Health, 45(3), 505-517. https://doi. org/10.1007/s10488-017-0841-y

Loeb, S., Dynarski, S., McFarland, D., Morris, P., Reardon, S., \& Reber, S. (2017). Descriptive analysis in education: A guide for researchers. (NCEE 2017-4023). Washington, DC: U.S. Department of Education, Institute of Education Sciences, National Center for Education Evaluation and Regional Assistance.

Lyon, A. R., \& Bruns, E. J. (2019). From evidence to impact: Joining our best school mental health practices with our best implementation strategies. School Mental Health, 11(1), 106-114. https://doi. org/10.1007/s12310-018-09306-w

Lyon, A., R., Cook, C. R., Brown, E. C., Locke, J., Davis, C., Ehrhart, M., \& Aarons, G. A. (2018). Assessing organizational implementation context in the education sector: Confirmatory factor analysis of measures of implementation leadership, climate, and citizenship. Implementation Science. https://doi.org/10.1186/ s13012-017-0705-6

Maenner, M. J., Shaw, K. A., Baio, J., Washington, A., Patrick, M., DiRienzo, M., Christensen, D. L., Wiggins, L. D., Pettygrove, S., Andrews, J. G., Lopez, M., Hudson, A., Baroud, T., Schwenk, Y., White, T., Rosnberg, C. R., Lee, L-C., Harrington, R. A., Huston, M., Dietz, P. M. (2020). Prevalence of autism spectrum disorder among children aged 8 years-autism and developmental disabilities monitoring network, 11 sites, United States, 2016. MMWR Surveillance Summaries, 69(4), 1-12. https://doi.org/10.15585/ mmwr.ss6904a1

Maryland State Department of Education. (2020, April 27). 2019 Maryland School Report Card. https://reportcard.msde.maryland.gov/
Meinck, S., \& Rodriguez, M. C. (2013). Considerations for correlation analysis using clustered data: working with the teacher education and development study in mathematics (TEDS-M) and other international studies. Large-Scale Assessments in Education. https:// doi.org/10.1186/2196-0739-1-7

Merikangas, K. R., He, J. P., Burstein, M., Swendsen, J., Avenevoli, S., Case, B., Georgiades, K., Heaton, L., Swanson, S., \& Olfson, M. (2011). Service utilization for lifetime mental disorders in US adolescents: Results of the national comorbidity survey-Adolescent supplement (NCS-A). Journal of American Academic Child Adolescent Psychiatry, 50(1), 32-45. https://doi.org/10.1016/j. jaac.2010.10.006

National Association of School Psychologists (2020). The Professional Standards of the National Association of School Psychologists. Author.

Newschaffer, C. J., Falb, M. D., \& Gurney, J. G. (2005). National autism prevalence trends from United States special education data. Pediatrics, 115(3), e277-e282.

Pas, E. T., Johnson, S. R., Larson, K. E., Brandenburg, L., Church, R., \& Bradshaw, C. P. (2016). Reducing behavior problems among students with autism spectrum disorder: Coaching teachers in a mixed-reality setting. Journal of Autism and Developmental Disorders, 46, 3640-3652. https://doi.org/10.1007/ s10803-016-2898-y

Payne, A. A. (2009). Do predictors of the implementation quality of school-based prevention programs differ by program type? Prevention Science, 10(2), 151. https://doi.org/10.1007/ s11121-008-0117-6

Powell, B. J., Fernandez, M. E., Williams, N. J., Aarons, G. A., Beidas, R. S., Lewis, C. C., McHugh, S. M., \& Weiner, B. J. (2019). Enhancing the impact of implementation strategies in healthcare: A research agenda. Frontiers in Public Health. https://doi.org/10. 3389/fpubh.2019.00003

Stadnick, N. A., Meza, R. D., Suhrheinrich, J., Aarons, G. A., Brookman-Frazee, L., Lyon, A. R., Mandell, D. S., \& Locke, J. (2019). Leadership profiles associated with the implementation of behavioral health evidence-based practices for autism spectrum disorder in schools. Autism, 23(8), 1957-1968. https://doi.org/10.1177/ 1362361319834398

Suhrheinrich, J., Rieth, S. R., Dickson, K. S., \& Stahmer, A. C. (2020). Exploring associations between inner-context factors and implementation outcomes. Exceptional Children, 86(2), 155-173. https://doi.org/10.1177/0014402919881354

Sun, S., Pan, W., \& Wang, L. L. (2010). A comprehensive review of effect size reporting and interpreting practices in academic journals in education and psychology. Journal of Educational Psychology, 102(4), 989-1004. https://doi.org/10.1037/a0019507

White, R. B., Polly, D., \& Audette, R. H. (2012). A case analysis of an elementary school's implementation of response to intervention. Journal of Research in Childhood Education, 26(1), 73-90. https://doi.org/10.1080/02568543.2011.632067

Williams, N. J., Wolk, C. B., Becker-Haimes, E. M., \& Beidas, R. S. (2020). Testing a theory of strategic implementation leadership, implementation climate, and clinicians' use of evidencebased practice: A 5-year panel analysis. Implementation Science, 15(1), 10.

Yau, H. K., \& Cheng, A. L. F. (2014). Principals and teachers' perceptions of school-based management. International Education Research, 2(1), 44-59.

Publisher's Note Springer Nature remains neutral with regard to jurisdictional claims in published maps and institutional affiliations. 